\title{
PENDIDIKAN SEKS DINI DAN KESEHATAN REPRODUKSI ANAK UNTUK SISWA SEKOLAH DASAR
}

\section{EARLY SEX EDUCATION AND CHILDREN'S REPRODUCTIVE HEALTH FOR ELEMNTARY SCHOOL STUDENTS}

\author{
Oleh: \\ Kurnia Dewiani, Yetti Purnama, Linda Yusanti \\ Prodi D3 Kebidanan Fakultas MIPA Universitas Bengkulu \\ kdewiani@unib.ac.id
}

\begin{abstract}
Cases of phenomena in the community are sexual violence that affects many kindergarten and elementary school students. Surveys and research in Indonesia prove the high cases of sexual crimes in children, the number of minors can access pornographic sites, the lack of supervision from their families, and the lack of explanation about sex. The role and responsibilities of an academician as well as a midwife's profession is to improve the health status of the community from newborn babies to old age. Midwives are community activists in the field of public health and safety. Some important tasks for midwives are as advocates, educators, facilitators, and health motivators. One of the duties of midwives as educators is to provide early sex education to elementary school students.

Sex education is information that aims to guide and care for everybody, from children to adults in terms of sexual relations in general and sexual life in particular. Early sex education is one way to prevent violence and sexual abuse in children. This activity has been carried out in two schools SD Negeri 24 Lingkar Timur and SD Negeri 83 Teluk Sepang Bengkulu City. The evaluation results show that there is an increase in children's knowledge about early sex and reproductive health, so that with this education children can prevent violence and sexual harassment and maintain good body health, and as a continuation of dedication has been formed a forum Bimbingan dan Konsling Seks Dini dan Kesehatan Reproduksi Anak in each school.
\end{abstract}

Keyword: Child Reproductive Health, Early Sex.

\section{ABSTRAK}

Kasus fenomena dimasyarakat saat ini adalah kekerasan seksual yang banyak menimpa siswa PAUD/TK dan SD. Ssurvey dan penelitian di Indonesia membuktikan tingginya kasus kejahatan seksual pada anak, banyaknya anak di bawah umur dapat mengakses situs-situs pornografi, kuangnya pengawasan dari keluarga, serta kurangnya penjelasan tentang seks. Maraknya kasus pelecehan dan kekerasan seks dikalangan masyarakat ini menyadarkan kita akan pentingnya mengembangkan materi pendidikan seks untuk anak usia dini dan kesehatan reproduksi anak.

Peran dan tanggung jawab seorang akademisi sekaligus berprofesi bidan adalah meningkatkan derajat kesehatan masyarakat mulai dari bayi baru lahir hingga usia lanjut. Bidan merupakan penggerak masyarakat dalam bidang kesehatan dan keselamatan masyarakat. Beberapa tugas penting bidan adalah sebagai advokator, edukator, fasilitator, dan motivator kesehatan. Salah satu tugas bidan sebagai edukator adalah memberikan pendidikan seks dini pada siswa sekolah dasar.

Pendidikan seks adalah penerangan yang bertujuan untuk membimbing serta mengasuh setiap anak laki-laki dan perempuan, sejak dari anak-anak sampai dewasa didalam prihal pergaulan antara kelamin pada umumnya dan kehidupan seksual pada khususnya. Pendidikan seks dini merupakan salah satu cara pencegahan terjadinya kekerasan dan pelecehan seksual pada anak. Kegiatan ini telah dilakukan di dua sekolah yaitu SD Negeri 24 Lingkar Timur dan SD Negeri 83 Teluk Sepang Kota Bengkulu. Hasil evaluasi diketahui bahwa adanya peningkatan pengetahuan anak tentang seks dini dan kesehatan reproduksinya, sehingga dengan adanya pendidikan ini anak-anak dapat mencegahan terjadinya kekerasan dan pelecehan seksual serta menjaga kesehatan tubuhnya secara baik, dan sebagai keberlanjutan pengabdian telah dibentuk wadah Bimbingan dan Konsling Seks Dini dan Kesehatan Reproduksi Anak di masing-masing sekolah.

Keyword: Kesehatan Reproduksi Anak, Seks Dini. 


\section{PENDAHULUAN}

Kasus yang tengah marak terjadi dimasyarakat saat ini adalah kekerasan seksual yang banyak menimpa siswa PAUD/TK dan SD. Dari berita-berita yang diangkat oleh berbagai media cetak dan elektronik akhir-akhir ini, terpotret secara suram anak-anak usia TK dan SD sebagai korban pelecehan dan kekerasan seksual. Anak-anak menjadi rentan terhadap kejahatan seksual. Hal yang memprihatinkan lagi adalah pelaku pelecehan dan kekerasan seksual itu bukan lah orang yang asing bagi anak-anak; mereka adalah orang-orang yang dekat di dalam kehidupan anak-anak (Purwaningsih, 2012).

Kemajuan teknologi informatika di Indonesia disatu sisi menjadi suatu kebanggaan, namun disisi lain sebagai suatu ancaman bagi perkembangan psikologis dan sosial anak, dengan mudahnya anak-anak dapat mengakses situs-situs pornografi karena tidak adanya pengawasan dari keluarga, kurangnya penjelasan tentang seks. Fenomena dan maraknya pornografi dikalangan masyarakat menyadarkan kita akan pentingnya mengembangkan materi pendidikan seks untuk anak usia dini. Sayangnya, seks masih dianggap sebagai hal yang tabu untuk dibicarakan oleh sebagian masyarakat. Hal ini tentu membuat banyak orang tua kesulitan untuk menyampaikan pendidikan seks yang tepat pada anak (Maryuni, 2016; Hastuti, 2012). Adanya kondisi atau fenomena seperti ini di masyarakat, maka kita sebagai akademisi Universitas Bengkulu dan sekaligus pemberi pelayanan kepada masyarakat perlu melakukan gerakan yang memberi hasil nyata khususnya dalam usaha preventif terjadi kekerasan dan pelecehan seksual pada anak-anak bangsa kita. Melalui dosen-dosen di Prodi D3 Kebidanan yang sekaligus berprofesi sebagai bidan memilki peran dan tanggung jawab meningkatkan derajat kesehatan masyarakat mulai dari bayi baru lahir hingga usia lanjut.

Bidan merupakan penggerak masyarakat dalam bidang kesehatan dan keselamatan masyarakat. Beberapa tugas penting bidan adalah sebagai advokator, edukator, fasilitator, dan motivator kesehatan. Salah satu tugas bidan sebagai edukator adalah memberikan pendidikan seks dini pada siswa sekolah dasar dan mengenalkan sistim kesehatan reproduksi. Pendidikan seks adalah penerangan yang bertujuan untuk membimbing serta mengasuh setiap anak laki-laki dan perempuan, sejak dari anak-anak sampai dewasa didalam prihal pergaulan antara kelamin pada umumnya dan kehidupan seksual pada khususnya. Melalui upaya pemberian pendidikan seks dini dan kesehatan reproduksi ini ke beberapa sekolah-sekolah dasar yang dianggap berisiko terjadinya kekerasan dan pelecehan seksual (Aprilia A, 2015).

Berdasarkan analisis kondisi yang ada pada penduduk daerah pasar dan pinggir pantai memiliki karakteristik pendidikan dan ekonomi masyarakat yang masih cukup rendah, dimana para orang tua sibuk berjualan sepanjang hari dan bernelayan sehingga kurang waktu untuk mengontrol dan memberi edukasi pada anak-anaknya. Berdasarkan hasil observasi dan diperoleh informasi bahwa pemberian edukasi tentang seks dini di SD di kota Bengkulu masih sangat minim. Untuk itu, para siswa SD sangat penting diberi pengetahuan tentang seks dini dan kesehatan reproduksi anak. Pendidikan seks dini ini merupakan salah satu cara pencegahan terjadinya pelecehan dan kekerasan seksual pada anak (Maryuni, 2016; Dokter Kecil, 2011). Tujuan dan manfaat pada pengabdian ini adalah untuk menambah pengetahuan dan pemahaman anak SD tentang seks dini dan kesehatan reproduksinya serta untuk membantu anak 
mengenali dan mencegah terjadinya pelecehan dan kekerasan seksual yang mengancam dirinya dan secara tidak langsung mengurangi angka kejahatan seksual pada anak usia dini.

\section{METODE PENGABDIAN}

Pengabdian dilaksanakan di sekolah SD Negeri 24 Lingkar Timur dan SD Negeri 83 Teluk Sepang Kota Bengkulu. Waktu implementasi dilaksanakan pada tanggal 7 Agustus 2018 untuk kegiatan di SD 83 Teluk Sepang dan tanggal 11 Agustus 2018 untuk SD Negeri 24 Lingkar Timur. Sebanyak 55 orang peserta mewakili SD Negeri 24 dan 55 orang siswa pada SD Negeri 83. Persiapan pengabdian ini melalui beberapa tahapan yaitu mulai dari melakukan survey lapangan, mengadakan pertemuan dengan pihak sekolah guna menjelaskan teknis kegiatan pengabdian,menyiapkan media untuk penyampaian materi berupa media power point, video, leaflet, benner, dan poster, belanja alat dan bahan untuk pelaksnaan kegiatan. Tahapan implementasi, anak-anak diberikan kuisioner pre-test sebelum implementasi dilakukan, sebagai baseline untuk mengetahui tingkat pengetahuan dan pemahaman para siswa tentang seks dini dan kesehatan reproduksinya. Metode yang digunakan adalah diskusi, presentasi, role play dan menayangkan video tentang pencegahan pelecehan dan kekerasan seks pada anak. Anak-anak diminta untuk mengahapal lagu yang ditayangkan dalam video, dan dilakukan evaluasi proses berupa meminta anak-anak menyanyikan ulang lagu tersebut hingga seluruh peserta bisa menyanyikannya dengan baik dan benar dan anak-anak dapat menjawab pertanyaan-pertanyaan yang diajukan pengabdi seputar materi yang telah disampaikan. Evaluasi akhir dilakukan 1 bulan setelah implementasi, untuk melihat keberhasilan kegiatan ini. Evaluasi kegiatan dengan memberikan kusioner post-test kepada sejumlah anak-anak yang juga telah mengikuti pre-test sebelumnya.

\section{HASIL DAN PEMBAHASAN}

Langkah awal yang dilaksanakan oleh tim pelaksana kegiatan pegabdian adalah melakukan observasi atau penjajakan calon mitra melalui wawancara dengan pihak sekolah. Hasil observasi dan wawancara diperoleh informasi seputar permasalahan yang ada pada siswa mereka, yaitu terkait kurangnya pengawasan orang tua, dan lingkungan anak setelah berada dilingkungan rumah. Karakteristik pendidikan dan ekonomi masyarakat daerah sekitar masih cukup rendah, dimana para orang tua sibuk berjualan sepanjang hari dan bernelayan sehingga kurang waktu untuk mengontrol dan memberi edukasi pada anak-anaknya. Berdasarkan hasil observasi dan diperoleh informasi bahwa pemberian edukasi tentang seks dini dan kesehatan reproduksi di SD di Kota Bengkulu masih sangat minim. Terdapat beberapa kejadian yang berkaitan dengan prilaku seks yang tidak diinginkan seperti kehamilan pada usia dini dan pergaulan bebas.

Implementasi telah dilaksanakan pada tanggal 7 Agustus 2018 untuk kegiatan di SD Negeri 83 dan tanggal 11 Agustus 2018 untuk SD Negeri 24. Saat implementasi anak-anak diberikan kusioner pre test sebagai baseline untuk mengetahui tingkat pengetahuan dan pemahaman para siswa tentang seks dini dan kesehatan reproduksinya. Sebanyak 55 orang peserta mewakili SD Negeri 24 dan 55 orang siswa pada SD Negeri 83. Rata-rata hasil yang didapat mencapai $90 \%$ anak sudah memiliki pengetahuan yang baik 
tentang organ tubunnya, menjaga kebersihan dirinya, hingga cara menjaga dirinya dari ancaman pelecehan dan kekerasan seksual. Materi yang disampaikan tentang hal-hal yang sangat penting yaitu :

1. Mengenalkan organ tubuh anak

2. Pertumbuhan dan perkembangan organ reproduksi

3. Cara menjaga kebersihan diri dan organ reproduksi

4. Cara pencegahan pelecehan dan kekerasan seksual pada anak

a. Sentuhan aman dan tidak aman

Anak-anak belum memahami mana sentuhan aman dan tidak aman. Memberi pengertian pada anak bahwa jika ada orang lain yang menyentuh area pribadi (mulut, dada, pantat, paha dan bagian kelamin). Batasan ini akan membuat anak mengerti bagian yang boleh disentuh dan tidak boleh disentuh oleh orang lain.

b. Rahasia baik dan buruk

Anak-anak yang menjadi korban pelecehan atau kekerasan seksual sering kali tidak bahagia. Mereka cendrung menyimpan rahasia karena tidak ingin diketahui atau mendapat ancaman dari pelaku. Mengajarkan anak-anak untuk membedakan rahasia baik dan buruk. Setiap hal yang membuat mereka tidak nyaman, guasar, ketakutan, dan kesedihan harus diberitahu atau diceritakan dan tidak boleh dirahasiakan.

c. Mencari perlindungan

Anak-anak harus diberi pemahaman tentang siapa saja yang patut dipercaya, dan mampu memberi perlindungan, misalnya orang tua, pihak sekolah, kepolisian, komisi perlindungan anak, dan lembaga lainnya. Anak-anak diberi pemahaman agar berani melaporkan jika ada orang lain tibatiba memberi "HADIAH" atau meminta untuk menyimpan rahasia, atau megajak pergi berdua saja tanpa tujuan yang jelas (Handayani N.H. 2012; Women Reserch Centre, 2016).

d. Orang tua, pihak sekolah, dan lingkungan yang peduli

Ketika anak-anak menjadi korban pelecehan atau kekerasan sekusal mereka cendrung menjadi pemalu, rendah diri, dan menyalahkan diri sendiri. Orang tua harus terbuka membicara hal tentang kesehatan reproduksi dan seks dini. Pastikan anak-anak mengerti kepada siapa mereka mengadu ketika mengalami hal yang tidak menyenangkan. Orang tua, pihak sekolah dan lingkungan harus mengerti bila ada perubahan prilaku pada anak (Women Reserch Centre, 2016).

Media implementasi yang digunakan adalah power point, leaflet, poster dan video. Metode yang digunakan adalah ceramah, diskusi, roleplay dan menayangkan video tentang pencegahan pelecehan dan kekerasan seks pada anak. Anak-anak diminta untuk mengahapal lagu yang ditayangkan dalam video, dan dilakukan evaluasi proses berupa meminta anak-anak menyanyikan ulang lagu tersebut hingga seluruh peserta bisa menyanyikannya dengan baik dan benar dan anak-anak dapat menjawab pertanyaanpertanyaan yang diajukan pengabdi seputar materi yang telah disampaikan. Sejumlah kelas dan tempattempat strategis benner atau poster agar anak-anak dapat membaca dan mempelajari materi tentang seks dini dan kesehatan reproduksi pada anak. 

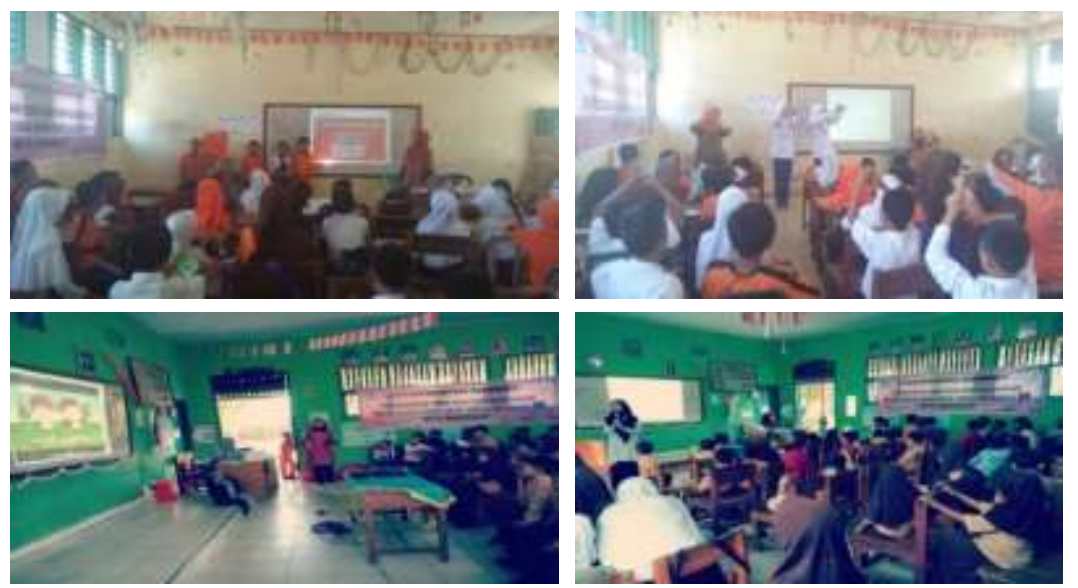

Gambar 1. Kegiatan siswa dalam mengikuti materi yang disampaikan

Evaluasi akhir dilakukan 1 bulan setelah implementasi, untuk melihat keberhasilan kegiatan ini. Evaluasi kegiatan dengan memberikan kusioner post-test kepada sejumlah anak-anak yang juga telah mengikuti pre-test sebelumnya. Hasil post-test mengalami peningkatan pengetahuan menjadi rata-rata $100 \%$ peserta bisa menjawab dengan benar, dan seluruh siswa bisa menjawab pertanyaan seputar materi serta siswa dapat mengulang lagu tentang pencegahan pelecehan dan kekerasan seksual dengan lancar. Selama pengabdian berlangsung tidak terdapat hambatan yang berarti tahapan kegiatan berjalan baik dan lancer. Penyambutan pihak sekolah baik dan sangat mendukung kegiatan ini untuk dilakukan secara berkelanjutan.
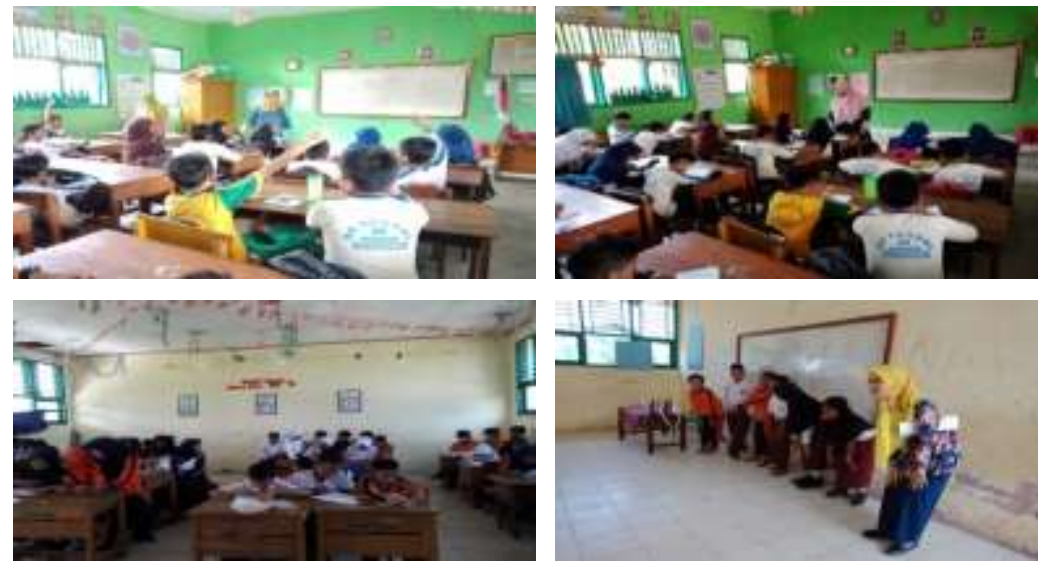

Gambar 2. Kegiatan tanya jawab dan bernyanyi bersama saat evaluasi

Keberlanjutan pengabdian ini adalah kami melakukan kerjasama dalam membentuk wadah "Bimbingan dan Konsling Seks Dini dan Kesehatan Reproduksi Anak di SD Negeri 24 Lingkar Timur dan SD Negeri 83 Teluk Sepang, dengan komitmen bahwa kapanpun terjadi masalah atau terdapat kegiatan sekolah yang membutuhkan kami terkait kesehatan anak khususnya masalah reproduksi anak, kami siap untuk dilibatkan. Dengan adanya wadah ini diharapkan menjadi upaya keberlanjutan pengabdian sebagai upaya perwujudan Tri Dharma Perguruan Tinggi Universitas Bengkulu. 

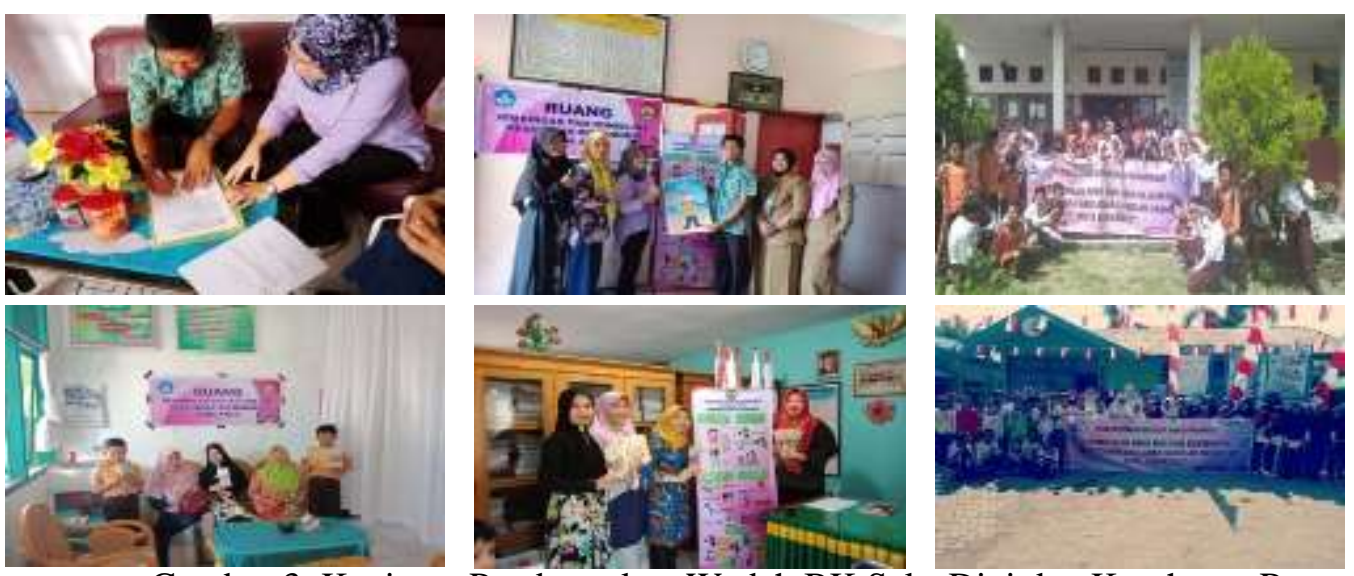

Gambar 3. Kegiatan Pembentukan Wadah BK Seks Dini dan Kesehatan Reproduksi Anak di SDN 24 dan 83.

\section{KESIMPULAN DAN SARAN}

\section{Kesimpulan}

1. Para peserta yaitu siswa SD Negeri 24 Lingkar Timur (Panorama) dan siswa SD Negri 83 Teluk Sepang Kota Bengkulu memperoleh tambahan pengetahuan dan pemahaman tentang seks dini dan kesehatan reproduksi pada anak.

2. Para peserta yaitu siswa SD Negeri 24 Lingkar Timur (Panorama) dan siswa SD Negri 83 Teluk Sepang Kota Bengkulu dapat mengenali dan mencegah terjadinya pelecehan dan kekerasan seksual yang mengancam dirinya

\section{Saran}

Kegiatan ini dapat dijadikan bahan pengetahuan dan pemahaman siswa tentang seks dini dan kesehatan reproduksi pada anak, serta anak dapat mengenali dan mencegah terjadinya pelecehan dan kekerasan seksual yang mengancam dirinya. Diharapkan kegiatan serupa juga dilakukan di sekolahsekolah yang lain, khusunya didaerah-daerah rawan terjadinya risiko pelecehan dan kekerasan seksual pada anak, seperti lokasi pasar dan pinggir pantai. Selama pelaksanaan hendaknya diikut sertakan semua siswa yang berada di lingkungan sekolah, agar semua siswa mendapat keseragaman informasi seputar seks dini dan kesehatan reproduksi anak.

\section{DAFTAR PUSTAKA}

Aprilia A, 2015, Perilaku Ibu dalam Memberikan Pendidikan Seks Usia Dini pada Nakan Pra Sekolah (Studi Deskriptif Eksploratif di TK IT Bina Insani Kota Semarang), Jurnal Kesehatan Masyarakat, Vol:3(1):619-628.

Handayani N.H, 2012, Pelecehan dan Kekerasan Seksual, Dikases http//Guetau.com/ informasi/hksr/ pelecehan dan kekerasan seksual.html, Tanggal 25 Januari 2018.

Hastuti S, 2014, Pendidikan Seksual Anak Di Tk Dan SD. Jurnal Sanata Dharma Berbagi,Yogyakarta,Vol:1.

Maryuni., Anggraeni L, 2016, Faktor yang Berhubungan dengan Tingkat Pengetahuan Orangtua tentang Pendidikan Seks secara Dini pada Anak Sekolah Dasar (SD), Jurnal Ners dan Kebidanan Indonesia, Vol:4(3):135-140.

Dokter Kecil, 2011, Pendidikan Seks (Sex Education) Sejak Dini...Kenapa Tidak???, Diakses:https//:dokterkecil.wordpress.com, 5 Februari 2018.

Purwaningsih W, 2012, Hubungan Pengetahuan dan Peran Keluarga dengan Perilaku Seksual Pra Nikah pada Remaja Anak Jalanan di Kota Surakarta, Jurnal Ilmu Kesehatan,Vol: 9(1): 22-29. 